\title{
Knockdown of microRNA-103a-3p inhibits the malignancy of thyroid cancer cells through Hippo signaling pathway by upregulating LATS1
}

\author{
M. L. ZHANG, W. H. SUN, H. Q. WU, Z. D. LIU, P. WANG* \\ Department of Thyroid Surgery, The Second Affiliated Hospital of Zhejiang University School of Medicine, Hangzhou, Zhejiang, China \\ ${ }^{*}$ Correspondence: p.wang@zju.edu.cn
}

Received December 24, 2019 / Accepted April 22, 2020

\begin{abstract}
MicroRNA (miR)-103a-3p has been shown to be involved in the development and progression of several types of cancer. However, the role of miR-103a-3p in thyroid cancer remains unclear. This study investigated the effects of miR-103a-3p on the biological characteristics of thyroid cancer cells and related mechanisms. In the present study, we found that the expression of miR-103a-3p was increased in thyroid cancer tissues compared to that in non-cancerous tissues. Additionally, the expression of miR-103a-3p in thyroid cancer cell lines (TPC-1, SW579, BHT101, K1) was markedly higher than that in the human thyroid cell line (Nthy-ori3-1). Silencing of miR-103a-3p obviously inhibited proliferation, migration, and invasion and promoted apoptosis of BHT101 cells. miR-103a-3p upregulation promoted the proliferation, migration, and invasion and inhibited apoptosis of K1 cells. Mechanistically, LATS1 was identified as a functional target of miR-103a-3p, and miR-103a-3p negatively regulated LATS1 expression. miR-103a-3p knockdown (or upregulation) partially reversed the effects of LATS1 knockdown (or overexpression) on proliferation, apoptosis, migration, and invasion of thyroid cancer cells. LATS1 knockdown inhibited the phosphorylation of YAP in BHT101 cells and promoted the nuclear translocation of YAP. Whereas, miR-103a-3p downregulation reversed the inhibitory effect of LATS1 knockdown on the Hippo signaling pathway. Moreover, overexpression of LATS1 induced YAP phosphorylation in K1 cells and inhibits nuclear translocation of YAP, and the upregulation of miR-103a-3p reversed this effect. The knockdown of miR-103a-3p inhibited tumor growth and progression in vivo. Taken together, knockdown of miR-103a-3p inhibits proliferation, migration, and invasion and promotes apoptosis of thyroid cancer cells through the Hippo signaling pathway by upregulating LATS1.
\end{abstract}

Key words: thyroid cancer, miR-103a-3p, large tumor suppressor 1, yes-associated protein, Hippo signaling pathway

The incidence of thyroid cancer accounts for 95\% of endocrine tumors, ranking the first in head and neck cancers [1]. Among all thyroid cancers, papillary thyroid cancer (PTC) accounts for about 70\% [2]. Although therapeutic treatments demonstrate a favorable prognosis, lymph nodes or distant metastases may also cause tumor recurrence or even death. The incidence of thyroid cancer has increased year by year. Understanding the mechanisms of thyroid cancer and exploring specific molecular targets will help to improve diagnosis, prognosis, and prevention.

MicroRNAs (miRNAs) are small molecule RNAs consisting of 20-25 nucleotides that do not have the function of encoding a protein. miRNAs are involved in a variety of cellular physiological processes by binding to the 3'UTR of their targeted mRNAs to degrade target mRNAs or inhibit translation. miRNAs can regulate a variety of cellular functions including proliferation, apoptosis, differentiation, and metastasis. There is increasing evidence that miRNAs can confer robustness to biological processes by modulating the target network $[3,4]$. For example, miR-126 regulates the recruitment of endothelial cells to metastatic breast cancer cells in vivo and in vitro by coordinating the targeting of IGFBP2/ IGF1/IGF1R and GAS6/MERTK signaling pathways [5]. In recent years, the relationship between miRNAs and tumors has received widespread attention. miRNAs can act as tumor suppressors or oncogenes in cancer cells. Abnormal levels of a range of miRNAs have been identified in thyroid cancer [6, 7], such as miR-146b, miR-221, and miR-222. miR-103a-3p is located on chromosome 11q24.1. Recent studies have shown that aberrant expression of miR-103a-3p is associated with the progression of several types of cancer [8-10], and several targets of miR-103a-3p have been validated in different models [11-13]. However, the role of miR-103a-3p in the progression of thyroid cancer remains unclear.

The Hippo signaling pathway has received widespread attention because of its role in cancer progression [14, 
15]. The current study showed that the Hippo pathway, as a signal, inhibits cell transformation and tumorigenesis [16]. The core portion of the Hippo signaling pathway in mammals is composed of upstream mammalian STE20like kinase 1/2 (MST1/2), salvador homolog 1 (SAV1), large tumor suppressor 1/2 (LATS1/2), downstream yes-associated protein (YAP), and transcriptional co-activator with PDZ-binding motif (TAZ). As one of the key factors in the Hippo signaling pathway, the downregulation of LATS1 can lead to the development of various cancers including colon cancer [17], gastric cancer [18], and cervical cancer [19]. Upon activation of the Hippo pathway, LATS1/2 kinase directly phosphorylates and inactivates the major effective factors of the Hippo pathway, YAP and TAZ, two major downstream effectors that mediate the transcription of the Hippo pathway [20]. Studies have found that miR-21 can resist radiation therapy by inhibiting the expression of LATS1 in cervical cancer cells [21]. However, the exact role of LATS1 and its regulation mechanism in thyroid cancer has not been reported. In this study, we demonstrated that LATS1 is the direct target of miR-103a-3p.

The present study investigated the expression of miR-103a-3p in thyroid carcinoma tissues and cell lines and analyzed the effects of miR-103a-3p knockdown or upregulation on proliferation, apoptosis, migration, and apoptosis of thyroid cancer cells. Additionally, we also found that miR-103 may regulate the Hippo signaling pathway by directly inhibiting the expression of LATS1 in thyroid cancer cells.

\section{Patients and methods}

Samples. A total of 43 thyroid cancer specimens and adjacent tissues from July 2017 to March 2019 were collected. Thyroid cancer patients were diagnosed by pathological diagnosis, and no chemotherapy or radiotherapy was performed before the specimen was obtained. The study was approved by the Ethics Committee of the Second Affiliated Hospital of Zhejiang University School of Medicine. Written informed consent was obtained from all patients.

Cell culture. Human thyroid cancer cell lines (TPC-1, SW579, BHT101, K1) and human thyroid cells Nthy-ori3-1 were supplied by the American Type Culture Collection (Manassas, VA, USA). The cell lines were placed in DMEM medium containing $10 \%$ fetal calf serum (FBS, Gibco, USA), $100 \mathrm{U} / \mathrm{ml}$ penicillin, $0.1 \mathrm{mg} / \mathrm{ml}$ streptomycin, and cultured in a $5 \% \mathrm{CO}_{2}$ incubator at $37^{\circ} \mathrm{C}$.

Quantitative reverse-transcription polymerase chain reaction (qRT-PCR). Total RNA in tissues and cells was extracted according to the Trizol kit (Invitrogen, USA). The miRNA portion was further purified using a miRNA isolation kit (Ambion, Austin, TX, USA). The synthesis of cDNA was carried out according to the instructions of the Reverse Transcription Kit (TaKaRa, Dalian, China). The PCR reaction was carried out using a qRT-PCR system (Applied Biosystems). GAPDH or U6 was used as an internal refer- ence. The relative expression of LATS1 or miR-103a-3p was calculated using the $2^{-\Delta \Delta \mathrm{Ct}}$ methods.

Transfection. miRNAs (miR-103a-3p mimic and negative control mimic-NC) and small interfering RNAs (siRNAs; si-miR-103a-3p and si-NC, si-LATS1 and si-Ctrl) were purchased from Sangon Biotech (Shanghai, China). LATS1 was synthesized from Sangon Biotech and cloned into pcDNA3.1 plasmid (Thermo Fisher Scientific, San Jose, CA, USA) to construct a LATS1 overexpression vector with the empty vector LATS1-Ctrl as a control. BHT101 and K1 cells were seeded into 6 -well plates $\left(2 \times 10^{6}\right.$ cells/well $)$, respectively. When the cells were fused to $70 \%$, plasmid or/and oligonucleotides were transfected into BHT101 or K1 as described by Lipofectamine 2000 (Invitrogen, CA, USA). The selection was accomplished with G418 (Sigma, St. Louis, MO, USA) at a concentration of $0.4 \mathrm{mg} / \mathrm{ml}$.

MTT assay. After transfection, cells were seeded in a 96-well culture plate $\left(1 \times 10^{5}\right.$ cells/well $) ; 3$ repeating wells for each group. For the blank well, only the same amount of cell culture medium was added into the blank well without inoculation of cells. The plates were placed in a $37^{\circ} \mathrm{C}, 5 \%$ $\mathrm{CO}_{2}$ incubator to culture for $24 \mathrm{~h}, 48 \mathrm{~h}$, or $72 \mathrm{~h}$. Then, $20 \mu \mathrm{l}$ of MTT solution was added to each well and incubated at $37^{\circ} \mathrm{C}$ for $4 \mathrm{~h}$. DMSO solution $(150 \mu \mathrm{l})$ was added to each well and incubated for $25 \mathrm{~min}$ at room temperature. The optical density at $490 \mathrm{~nm}$ (OD490) was measured using a microplate reader (Thermo Fisher Scientific, USA).

Flow cytometry. At $48 \mathrm{~h}$ post transfection, cells were harvested. The cells were washed with PBS, centrifuged at $1000 \mathrm{r} / \mathrm{min}$ for $5 \mathrm{~min}$, and the supernatant was discarded. The cells were resuspended in PBS to a concentration of $1 \times 10^{5}$ cells $/ \mathrm{ml}$. After fixing with $1 \mathrm{ml}$ of pre-cooled $70 \%$ ethanol, the cells were transferred into a $1.5 \mathrm{ml}$ Eppendorf tube. Subsequently, $5 \mu \mathrm{l}$ of Annexin V-FITC was added to the tube and incubated for $15 \mathrm{~min}$ in the dark at room temperature. $5 \mu$ of propidium iodide (PI) was added into the tube and incubated for $10 \mathrm{~min}$ in the dark. The proportion of apoptotic cells was measured on a flow cytometer (FACSCalibur, BD Biosciences, San Jose, CA, USA).

Wound healing assay. Cells were trypsinized and re-inoculated into a 6 -well plate $\left(5 \times 10^{5}\right.$ cells/well $)$. Cells were serum-starved for 12 hours in a serum-free medium before producing the scratch wound. After the cells covered the bottom of the well plate, a $10 \mu \mathrm{l}$ tip was used to scratch the bottom of the 6-well plate. The plate was gently washed with PBS to remove the floating cells. The medium without FBS was added into the culture plate, and the cell culture continued in an incubator with $5 \% \mathrm{CO}_{2}$ at $37^{\circ} \mathrm{C}$. Photographs were taken under an inverted microscope (Olympus, Japan) at 0 and $48 \mathrm{~h}$, respectively. The gap distance was quantitatively evaluated using the ImageJ software (National Institutes of Health, Bethesda, MD, USA). The experiment was repeated three times.

Transwell assay. The transfected cells were trypsinized and resuspended in serum-free medium. $200 \mu \mathrm{l}$ of the cell 
suspension was added into the upper chamber of a Matrigelcoated Transwell chamber (BD Biosciences, Franklin Lakes, NJ, USA). $800 \mu \mathrm{l}$ of DMEM medium containing 10\% FBS was added into the lower chamber of the Transwell chamber. Cells were cultured at $37^{\circ} \mathrm{C}$ in an incubator with $5 \% \mathrm{CO}_{2}$ for $48 \mathrm{~h}$. Subsequently, the chamber was fixed with $4 \%$ paraformaldehyde for $30 \mathrm{~min}$ and stained with $0.1 \%$ crystal violet for $10 \mathrm{~min}$. Cells in the upper chamber were wiped with a cotton swab. Five fields of view were randomly selected from each well for cell counting under an inverted microscope, and the average value was calculated. The experiment was repeated three times.

Dual-luciferase reporter assay. LATS1 containing the predicted binding sites with miR-103a-3p or with mutated binding sites were cloned into the pmirGLO dual-luciferase reporter vector (Promega, Madison, WI, USA). BHT101 or $\mathrm{K} 1$ cells $\left(3 \times 10^{4} /\right.$ well $)$ were seeded into 24 -well plates and co-transfected with miR-103a-3p mimic (or miR-NC) and luciferase reporter vectors according to Lipofectamine 2000 (Invitrogen). After $48 \mathrm{~h}$, the luciferase activity was detected by the Lucifer Reporter Assay System (Promega, Madison, WI, USA).

Western blot assay. The cells were cultured for $48 \mathrm{~h}$ after transfection. Protein concentration was determined using a BCA protein assay kit (Thermo Fisher Scientific). After 25 $\mu \mathrm{g}$ of the sample was separated by $12 \%$ polyacrylamide gel electrophoresis, the proteins on the gel were transferred to a PVDF membrane (Millipore, Bellerica, MA, USA). The membrane was placed in 5\% skim milk and blocked at room temperature for $1 \mathrm{~h}$. After the completion of the blocking, the membrane was incubated with the corresponding primary antibody overnight at $4^{\circ} \mathrm{C}$. After TBST washing, the membrane was incubated with the secondary antibody for $2 \mathrm{~h}$ at room temperature. Proteins were visualized using ECL (Pierce, Rockford, IL USA). Images were captured using DNR Bio Imaging Systems (Jerusalem, Israel).

Xenograft assay. BALB/c nude mice (weight 21-25 g, aged 4 weeks) were purchased from Beijing Vital River
Animal Company (Beijing, China) and reared under specific pathogen-free conditions. The mice received sterile rodent chow and water ad libitum and were maintained on a $12 \mathrm{~h}$ light/dark cycle in a controlled temperature $\left(24 \pm 1^{\circ} \mathrm{C}\right)$ and humidity $55 \%$. All procedures were conducted according to the National Institutes of Health Guide for the Care and Use of Laboratory Animals and approved by the Animal Ethics Committee of the Second Affiliated Hospital of Zhejiang University School of Medicine. BHT101 cells $\left(1.5 \times 10^{6} \mathrm{cells} / \mathrm{ml}\right)$ stably expressing miR-103a-3p siRNA, suspended in $100 \mu \mathrm{l}$ of PBS, were injected subcutaneously into the right flank of nude mice (6 per group). Tumor volume $\left(0.5 \times\right.$ length $\times$ width $\left.^{2}\right)$ was measured every week. After 5 weeks, mice were sacrificed, and the tumor was excised and weighed.

Statistical analysis. SPSS 19.0 software (SPSS, Inc., Chicago, IL, USA) was used for statistical analysis. Data are expressed by mean \pm standard deviation (SD). The differences between the two groups were assessed using the Student's t-test. The comparison of more than two groups was conducted using the one-way analysis of variance. The linear correlation coefficient (Pearson's $r$ ) was used to estimate the correlation between miR-103a-3p and LATS1 expression. A p-value $<0.05$ was considered to indicate a statistically significant difference.

\section{Results}

miR-103a-3p is upregulated in human thyroid carcinoma tissues and cell lines. The expression of miR-103a-3p in 43 thyroid carcinoma tissues was significantly higher than that in adjacent non-tumor tissues (Figure 1A). The expression of miR-103a-3p was significantly upregulated in thyroid cancer cell lines (TPC-1, SW579, BHT101, and K1) compared to human thyroid cancer cell line Nthy-ori3-1 (Figure 1B). Subsequent experiments were performed using cell lines BHT101 and K1 with a relatively higher expression of miR-103a-3p.
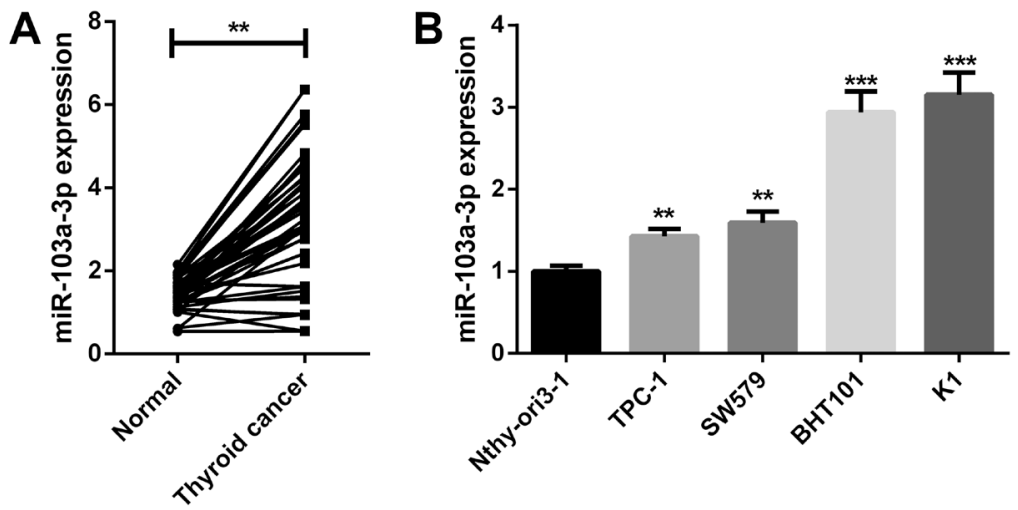

Figure 1. miR-103a-3p is upregulated in human thyroid carcinoma tissues and cell lines. A) qRT-PCR was used to detect the expression of miR-103a-3p in thyroid cancer and non-tumor tissues, $n=43$. B) The expression of miR-103a-3p in thyroid cancer cell lines (TPC-1, SW579, BHT101, K1) and human thyroid cells (Nthy-ori3-1) was analyzed by $\mathrm{qRT}-\mathrm{PCR} .{ }^{* *} \mathrm{p}<0.01,{ }^{* * *} \mathrm{p}<0.001$ 
Effects of miR-103a-3p on the proliferation, apoptosis, migration, and invasion of thyroid cancer cells. To further investigate the biological function of miR-103a-3p in thyroid cancer, we transfected miR-103a-3p siRNA (si-miR-103a-3p) and its negative control (si-NC) into BHT101 cell, while miR-103a-3p mimic and its negative control (mimic-NC) were transfected into K1 cells. qRT-PCR results showed that the expression of miR-103a-3p in the si-miR-103 group was significantly lower than that in the si-NC group in the BHT101 cells, whereas the expression of miR-103a-3p in the miR-103-mimic group was significantly higher than that in the mimic-NC group in the K1 cells (Figure 2A).

We further analyzed the effects of miR-103a-3p on the biological properties of thyroid cancer cell lines. The MTT assay showed (Figure $2 \mathrm{~B}$ ) that miR-103a-3p silencing significantly inhibited the proliferation of BHT101 cells compared to the si-NC group. Compared with the mimic-NC group, the miR-103a-3p upregulation obviously promoted the proliferation of $\mathrm{K} 1$ cells. Apoptosis was further detected by flow cytometry (Figure 2C). The apoptotic rate of BHT101 cells in the si-miR-103a-3p group was significantly higher than that in the si-NC group, while the apoptosis rate of $\mathrm{K} 1$ cells in the miR-103a-3p-mimic group was markedly lower than that in the mimic-NC group. Wound healing assay analysis showed that si-miR-103a-3p significantly inhibited the migration of BHT101 cells, while miR-103a-3p mimic significantly promoted the migration of $\mathrm{K} 1$ cells (Figure $3 \mathrm{~A}$ ). Additionally, transwell assay also showed that miR-103a-3p silencing significantly inhibited BHT101 cell invasion, while miR-103a-3p upregulation significantly promoted $\mathrm{K} 1$ cell invasion (Figure $3 \mathrm{~B}$ ). These results confirmed that miR-103a-3p might play a carcinogenic role by promoting proliferation, migration, and invasion, and inhibiting apoptosis of thyroid cancer cells.

miR-103a-3p downregulates LATS1 expression. Furthermore, we found that the expression of LATS1 mRNA in thyroid carcinoma tissues was significantly lower than that in normal tissues (Figure 4A), and the expression level of miR-103a-3p in thyroid carcinoma tissues was significantly negatively correlated with LATS1 (Figure 4B). Additionally, we found the binding sequence of miR-103a-3p in 3'UTR of LATS1 mRNA through TargetScan, a bioinformatics tool available online. The binding sites of miR-103a-3p and LATS1 are shown in Figure 4C. The dual-luciferase reporter
A

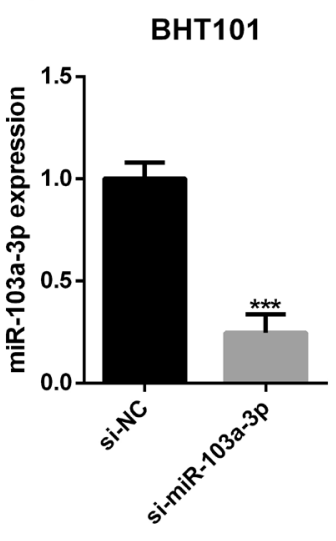

C

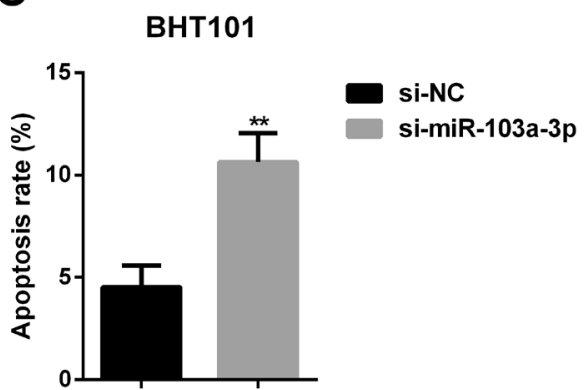

B

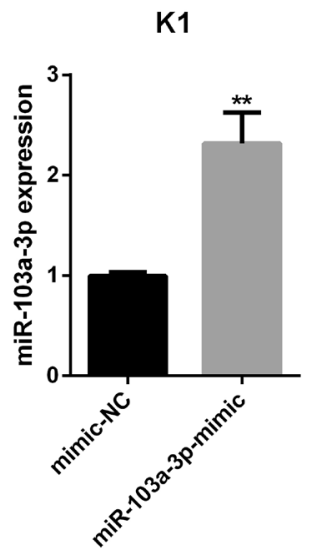

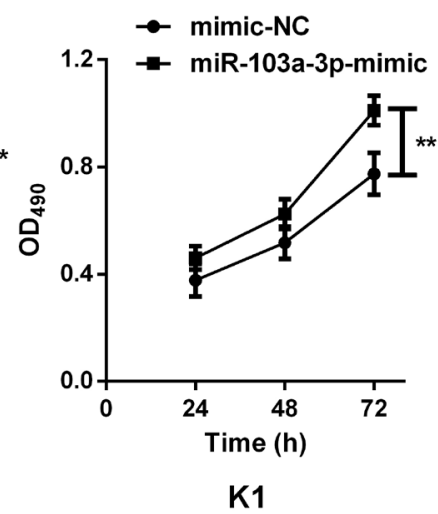

$\mathrm{K} 1$

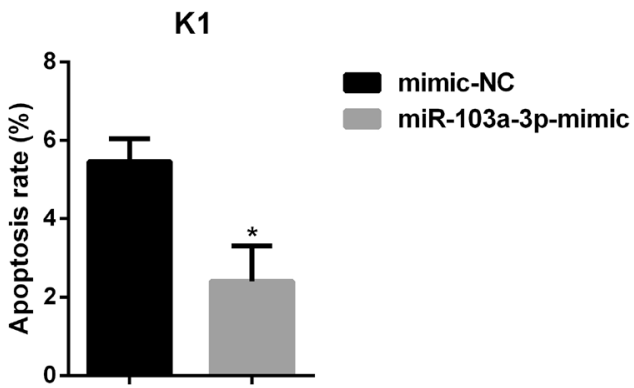

Figure 2. Effects of miR-103a-3p on the proliferation and apoptosis of thyroid cancer cells. A) qRT-PCR was used to detect the expression of miR-103a3 in BHT101 and K1 cells. B) miR-103a-3p knockdown inhibited the proliferation of BHT101 cells, while the upregulation of miR-103a-3p promoted the proliferation of $\mathrm{K} 1$ cells. C) miR-103a-3p knockdown promoted apoptosis of BHT101 cells, while the upregulation of miR-103a-3p inhibited apoptosis of $\mathrm{K} 1$ cells. ${ }^{*} \mathrm{p}<0.05,{ }^{* *} \mathrm{p}<0.01,{ }^{* *} \mathrm{p}<0.001$ 
A

BHT101
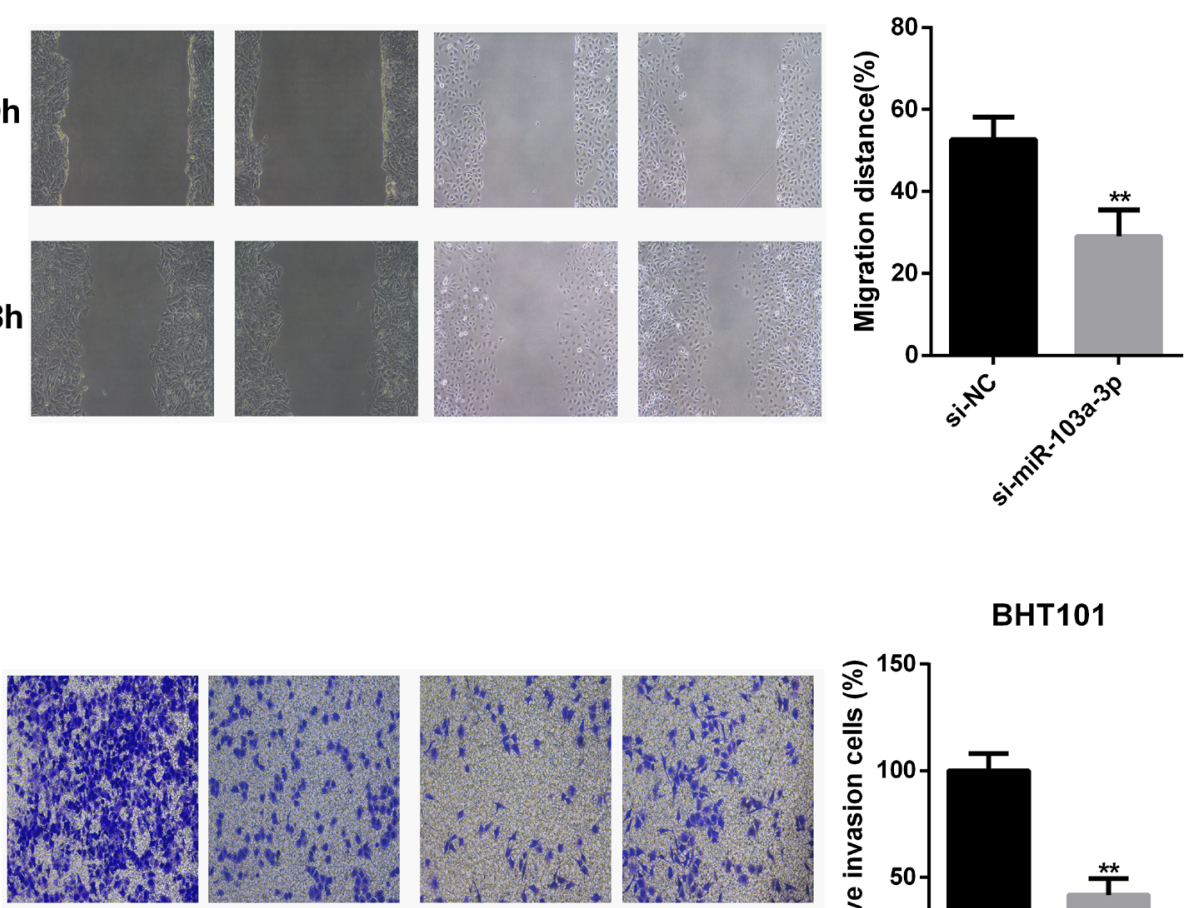

BHT101

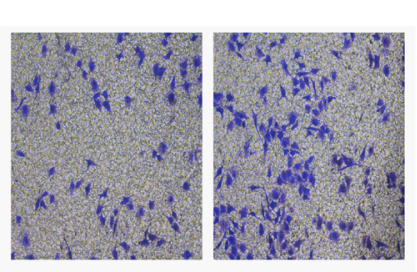

K1
BHT101
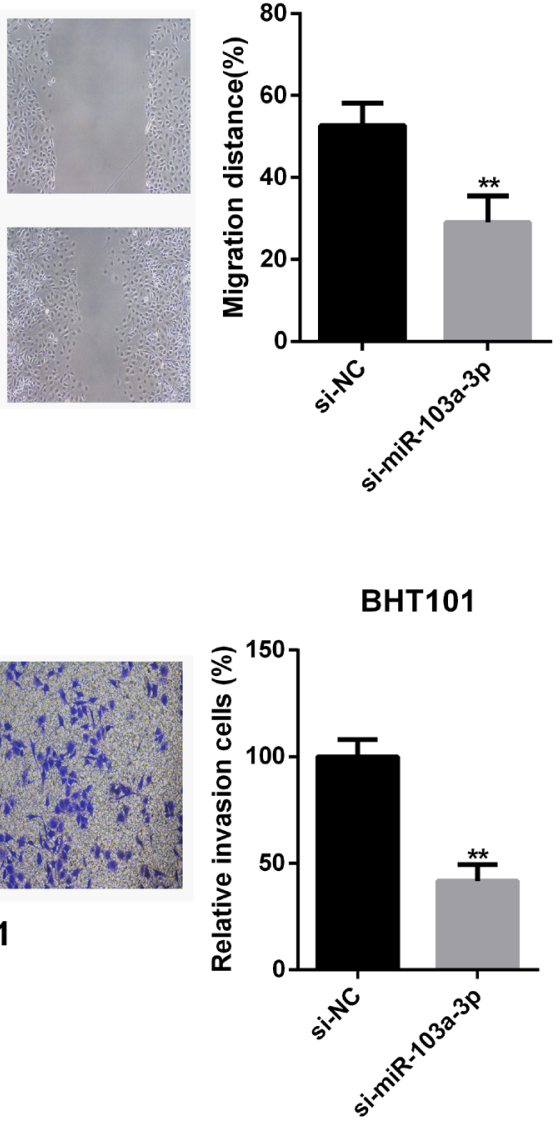

$\mathrm{K} 1$

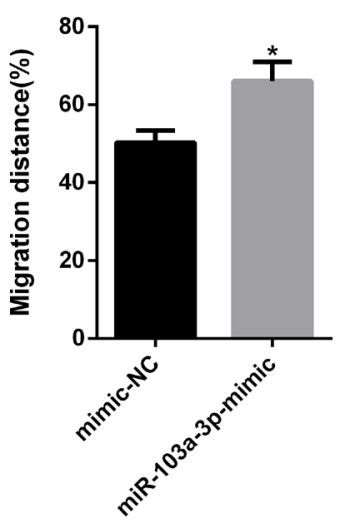

K1

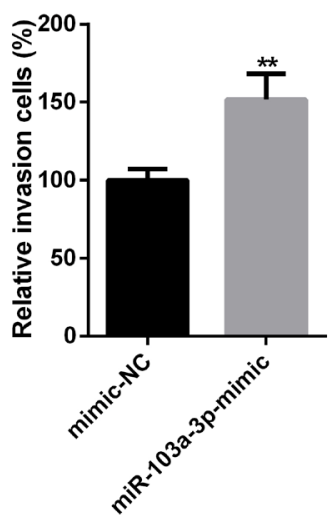

Figure 3. Effects of miR-103a-3p on the migration (A) and invasion (B) of thyroid cancer cells. miR-103a-3p knockdown inhibited migration and invasion of BHT101 cells and miR-103a-3p upregulation promoted migration and invasion of $\mathrm{K} 1$ cells. ${ }^{*} \mathrm{p}<0.05,{ }^{* *} \mathrm{p}<0.01$

assay confirmed that miR-103a-3p reduced the luciferase activity of the LATS1-Wt luciferase reporter in BHT101 and K1 cells (Figure 4D). qRT-PCR and western blot analysis showed that silencing of miR-103a-3p significantly increased the expression of LATS1 mRNA (Figure 4E) and protein (Figure 4F) in thyroid cancer cell line BHT101, while upregulation of miR-103a-3p significantly inhibited the expression of LATS1 mRNA and protein in K1 cells (Figures 4E, $4 \mathrm{~F})$. These results suggested that miR-103a-3p is capable of negatively regulating the expression of LATS1.

miR-103a-3p regulates proliferation, apoptosis, migration, and invasion of thyroid cancer cells by regulating LATS1 expression. To investigate whether miR-103a-3p promotes thyroid cancer by negatively regulating LATS1, si-LATS1 was transfected into BHT101 cells, or along with si-miR-103a-3p, while the LATS1 overexpression vector (LATS1) was transfected into K1 cells, or along with miR-103a-3p-mimic. The results showed that the transfec- tion of si-LATS1 evidently downregulated the expression of LATS1 protein in BHT101 cells, while the overexpression of LATS1 markedly increased the expression of LATS1 protein in $\mathrm{K} 1$ cells (Figure 5A).

Next, we analyzed the effects of LATS1 knockdown or overexpression on the biological characteristics of thyroid cancer cells. As a result, it was found that LATS1 knockdown promoted proliferation (Figure 5B), migration, (Figure $6 \mathrm{~A}$ ), and invasion (Figure 6B), and inhibited apoptosis (Figure 5C) of BHT101 cells. In contrast, overexpression of LATS1 inhibited proliferation, migration, and invasion, and promoted apoptosis of $\mathrm{K} 1$ cells. Most importantly, the introduction of si-miR-103a-3p partially abolished the effects of LATS1 knockdown on BHT101 cells. And miR-103a-3p mimic also reversed the anti-cancer effect induced by LATS1 overexpression in K1 cells (Figures 5B, 5C, 6A, 6B).

miR-103a-3p regulates Hippo signaling through inhibition of LATS1. YAP is the most typical effector of the Hippo 
A

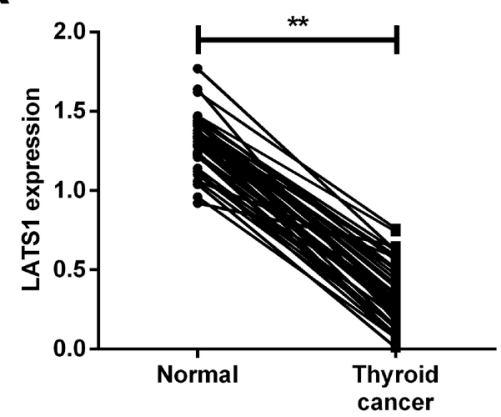

B

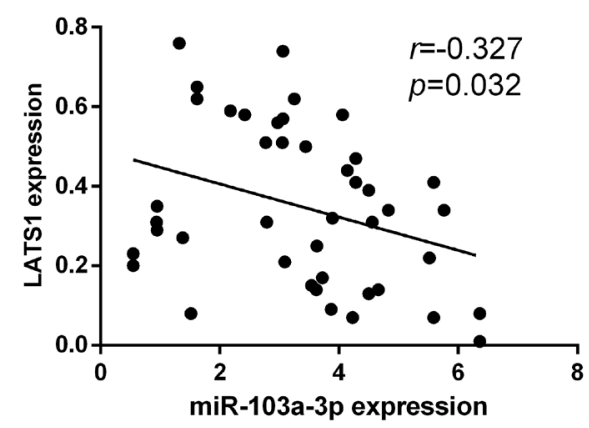

C

LATS1-Mut 5' atATTGGTATTTTTGAACGACGt 3'

LATS1-Wt 5' atATTGGTATTTTTGATGCTGCt 3' || ||| miR-103a-3p 3' agUAUCGGGACAUGUUACGACGa 5'

D
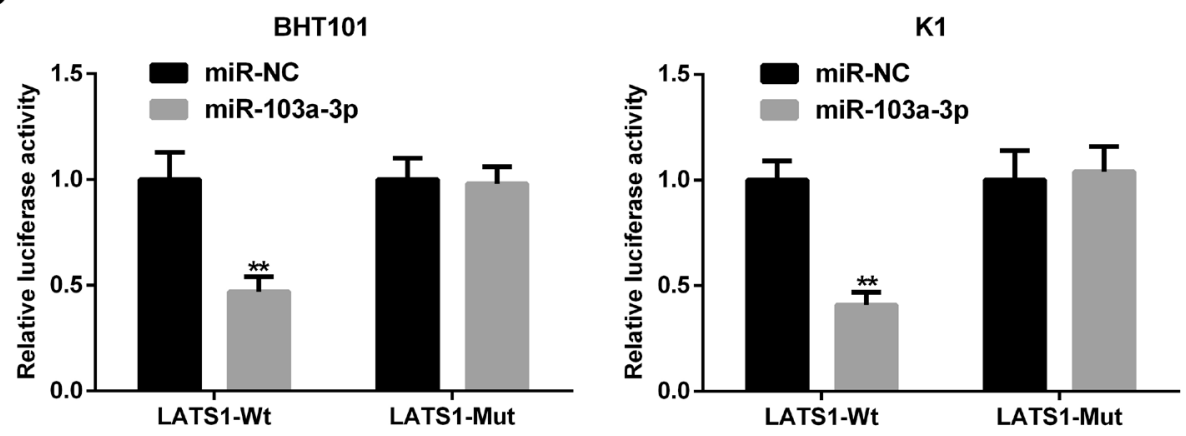

$\mathbf{E}$

$\mathbf{F}$
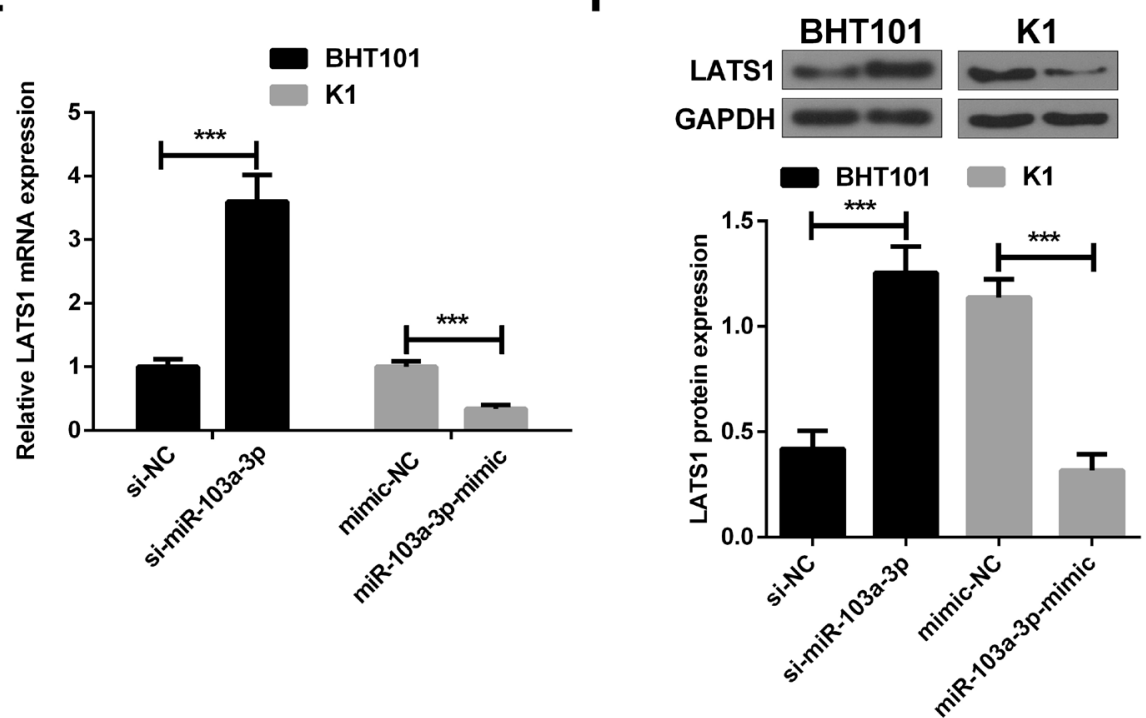

Figure 4. miR-103a-3p inhibits LATS1 expression. A) The expression of LATS1 protein was downregulated in thyroid cancer tissues. B) A negative correlation between miR-103a-3p and LATS1 protein levels in thyroid cancer tissues. C) Schematic illustration of LATS1 binding sites in miR-103a3p. D) Luciferase reporter activity in BHT101 and K1 cells was analyzed after co-transfection with miR-103a-3p (or miR-NC) and luciferase reporters containing LATS1-Mut or LATS1-Wt. The expression levels of LATS1 mRNA (E) and protein (F) in BHT101 cells and K1 cells were analyzed by western blot assay. ${ }^{* *} \mathrm{p}<0.01,{ }^{* * *} \mathrm{p}<0.001$ 
A
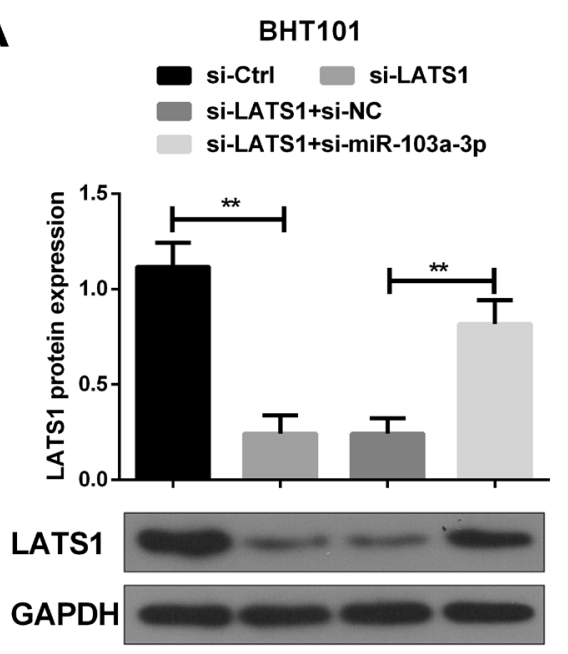

B

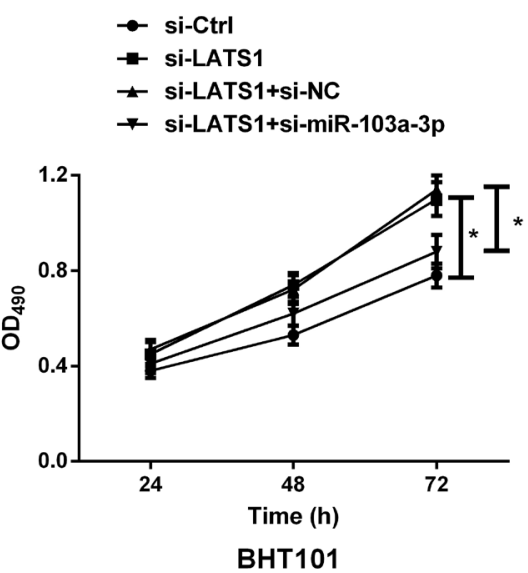

C

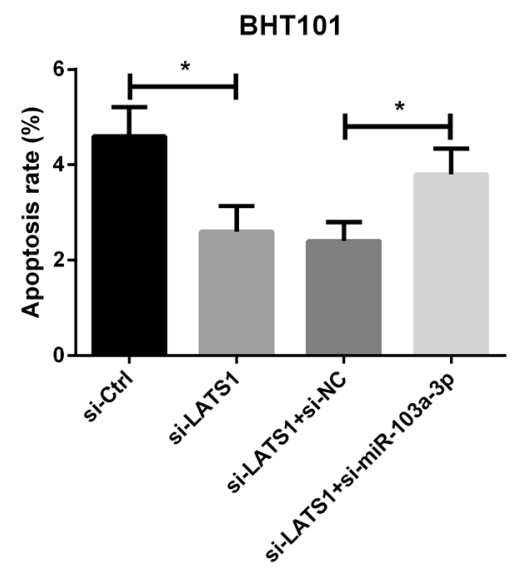

\section{K1}

LATS1-Ctrl LATS1

LATS $1+$ mimic-NC

LATS1+miR-103a-3p-mimic

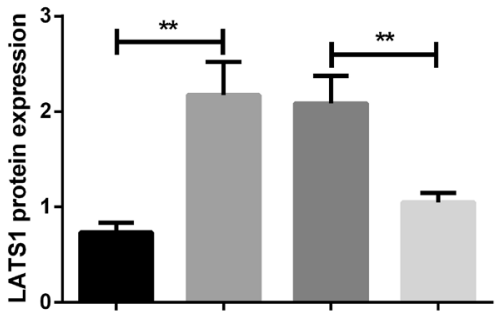

LATS1

GAPDH

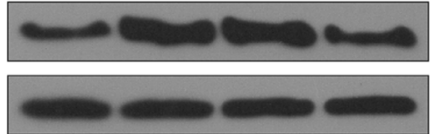

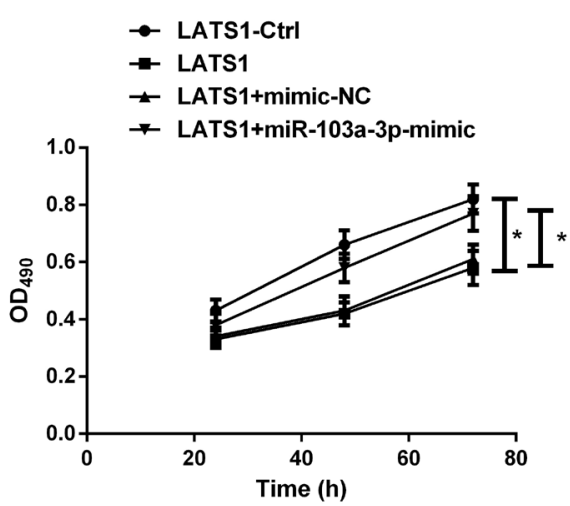

K1

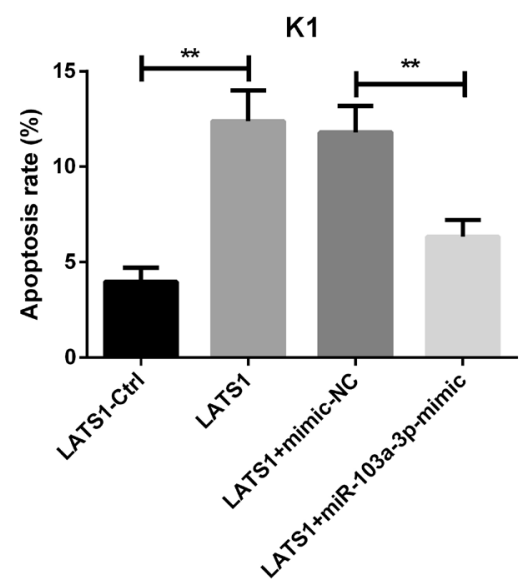

Figure 5. miR-103a-3p regulates proliferation, apoptosis of thyroid cancer cells via regulating LATS1. A) Western blot was used to detect the expression of LATS1 protein in cells. B) Downregulation of miR-103a-3p reversed the promotion effect of LATS1 knockdown on the proliferation of BHT101 cells, while the upregulation of miR-103a-3p reversed the inhibitory effect of LATS1 overexpression on K1 cell proliferation. C) Flow cytometry was used to analyze apoptosis in BHT101 and K1 cells after transfection. The introduction of si-miR-103a-3p partially abolished the inhibitory effects of LATS1 knockdown on apoptosis of BHT101 cells. Overexpression of LATS1 promoted apoptosis of K1 cells, but this action was attenuated by the upregulation of miR-103a-3p. ${ }^{*} \mathrm{p}<0.05,{ }^{* *} \mathrm{p}<0.01$ 
pathway [22]. Direct phosphorylation of YAP by LATS1 on multiple serine residues results in the inactivation of YAP [23]. Western blot assay showed that the LATS1 knockdown significantly inhibited YAP phosphorylation in BHT101 cells (Figures 7A, 7B). Simultaneously, LATS1 knockdown reduced the level of YAP protein in the cytoplasm and increased the content of YAP protein in the nucleus (Figures 7A, 7B). In contrast, LATS1 overexpression significantly increased the phosphorylation level of YAP protein in K1 cells (Figures 7A, 7C). Meanwhile, overexpression of LATS1 increased the content of YAP protein in the cytoplasm and decreased the level of YAP protein in the nucleus. These results suggested that LATS1 knockdown could inhibit the activation of the Hippo pathway by inhibiting YAP phosphorylation in the cytoplasm and promoting nuclear translocation of YAP. Moreover, miR103a-3p downregulation reversed the nuclear translocation of YAP induced by si-LATS1, while miR-103a-3p mimic abolished the activation of the Hippo pathway induced by LATS1 overexpression (Figures 7A-7C). These results suggested that miR-103a-3p inhibits the activation of the Hippo signaling pathway by inhibiting the expression of LATS1.

Knockdown of miR-103a-3p attenuates tumor growth in the xenograft model. To confirm the in vitro results, we determined the effect of miR-103a-3p knockdown on tumor growth in the xenograft model. Compared with the si-NC group, tumor volume (Figure 8A) and weight (Figure 8B) in the si-miR-103a-3p group were significantly reduced. Similarly, compared with the si-NC group, the expression of miR-103a-3p in tumor tissue of mice in the si-miR-103a-3p group was markedly reduced (Figure $8 \mathrm{C}$ ). These results suggested that the miR-103a-3p knockdown inhibits tumor growth of thyroid cancer in vivo.

\section{Discussion}

As an endogenous regulator, miRNAs act as oncogenes or tumor suppressor genes in tumor development. miR-103a-3p has been shown to be closely associated with many types of cancer [8-13]. However, the expression and role of miR-103a-3p in thyroid cancer remain unclear. In the present study, we found that miR-103a-3p was upregulated in thyroid cancer tissues and cells, and regulated the proliferation, apoptosis, migration, and invasion of thyroid cancer cells. Further studies on the mechanism suggested that miR-103a-3p might be involved in the development of thyroid cancer by inhibiting the expression of LATS1 to regulate the Hippo signaling pathway.

miR-103a-3p has different expression patterns in different tissues. It acted as both a cancer-promoting factor and a tumor suppressor. For example, Fasihi et al. [24] found that miR-103a-3p is highly expressed in colorectal cancer tissues and activates the cancer-promoting Wnt signaling pathway. However, Yu et al. [8] showed that miR-103a-3p is downregulated in glioma tissues and glioma stem cells
(GSCs), and acts as a tumor suppressor molecule to inhibit the proliferation, migration, and invasion and to promote apoptosis of CSCs by blocking forebrain embryonic zinc finger protein 1(FEZF1)/cell division cycle 25A (CDC25A) pathway. Additionally, miR-103a-3p may have different biological effects in the same tumor tissue. For example, Liang et al. [25] found that miR-103a-3p is downregulated in gastric cancer tissues and gastric cancer cells MGC-803, and the upregulation of miR-103a-3p inhibits cell proliferation, migration, and invasion. However, Hu et al. [12] showed that miR-103a-3p is highly expressed in gastric cancer tissues and is involved in promoting the proliferation of gastric cancer cells. The function of miR-103a-3p in cancer is still controversial. In this study, we found that the expression of miR-103a-3p in thyroid cancer tissues was significantly higher than that in adjacent tissues. Simultaneously, the expression level of miR-103a-3p in thyroid cancer cell lines was significantly higher than that of normal thyroid cell line Nthy-ori3-1.

Increased proliferative capacity, decreased apoptosis, and enhanced invasion and migration are common biological features of tumor cells and the basis for tumor growth, metastasis, and recurrence [26, 27]. To further investigate the function of miR-103a-3p in thyroid cancer, we transfected the thyroid cancer cell line BHT101 with si-miR$103 a-3 p$. Consistent with the expectations, we found that the silencing of miR-103a-3p significantly inhibited proliferation, migration, and invasion and promoted apoptosis of BHT101 cells. Furthermore, after transfection of the thyroid cancer cell line $\mathrm{K} 1$ with miR-103a-3p mimic, we observed the opposite results. These results may explain the upregulation of miR-103a-3p in cancerous tissues. Therefore, we speculated that miR-103a-3p might play a vital role in promoting the development of thyroid cancer. miR-103a-3p decreases the expression of LATS1. Moreover, miR-103a-3p was also negatively correlated with LATS1 in thyroid cancer tissues. Previous studies have shown that miR-103a-3p can activate the JNK/STAT and the mTOR signaling pathways to inhibit the apoptosis by targeting p57 [28], and promote cell proliferation in gastric cancer by targeting activating transcription factor 7 [12]. These studies demonstrate that miRNAs play a key role in the complex gene regulatory networks by regulating their targets. Moreover, Zhong et al. [11] confirmed that circular RNA TCF25 acts as a sponge of miR-103a-3p to inhibit its expression in bladder carcinoma. Yu et al. [8] showed that the expression of miR-103a-3p might be regulated by long-chain non-coding RNA 00152 in glioma stem cells. Here, we focus on the function of miR-103a-3p and its downstream regulatory mechanism in thyroid cancer. A previous paper showed that miR-103 functions as an oncogene to exacerbate the metastasis and EMT of hepatocellular carcinoma [29]. However, it remains unknown whether miR-103 can also exert cancer-promoting function in thyroid cancer. In this study, our findings suggested that miR-103a-3p is an oncogene in thyroid cancer, contributing 
A
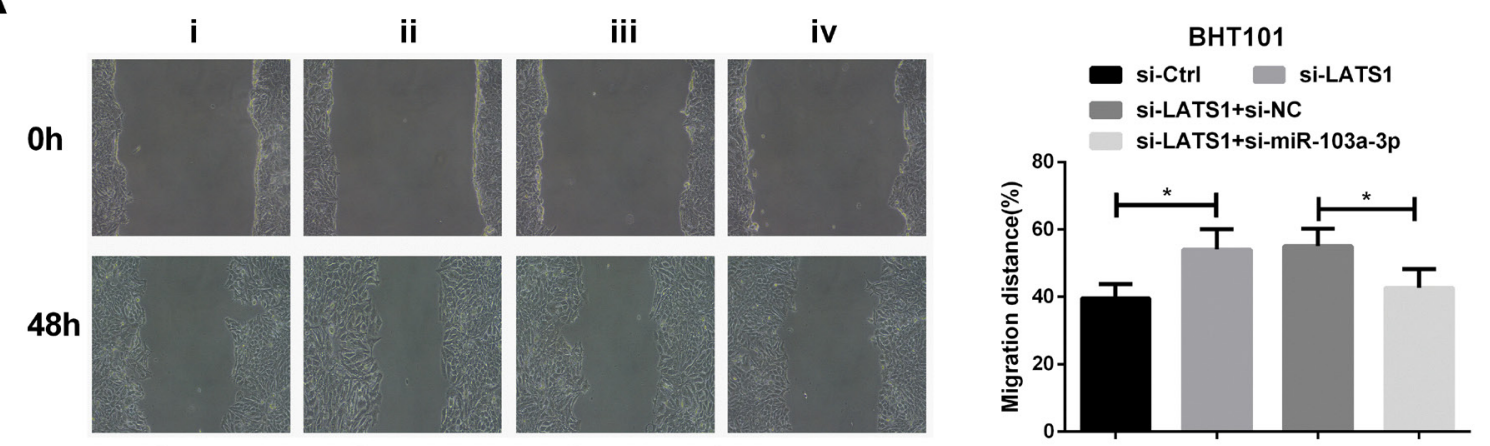

i:si-Ctrl; ii:si-LAST1; iii:si-LAST1+si-NC; iv:si-LAST1+si-miR-103a-3p
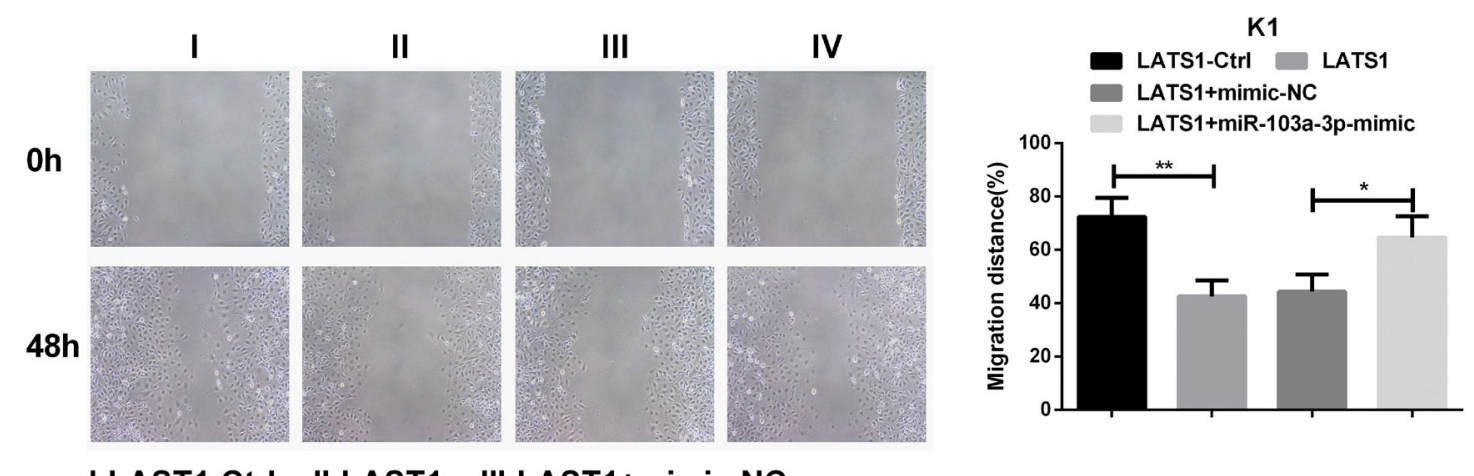

I:LAST1-Ctrl; II:LAST1; III:LAST1+mimic-NC;

IV:LAST1+miR-103a-3p-mimic

\section{B}

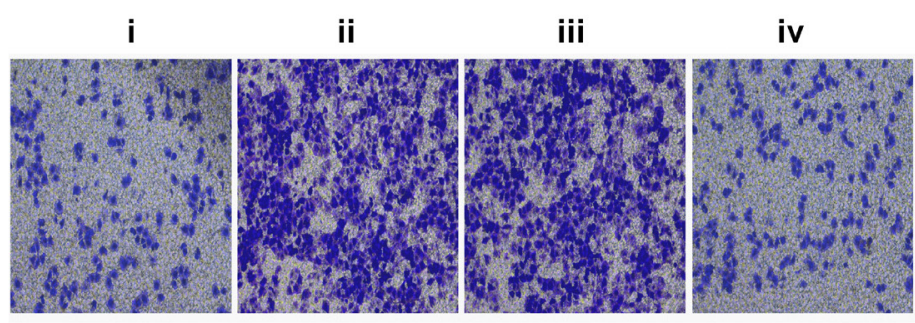

i:si-Ctrl; ii:si-LAST1; iii:si-LAST1+si-NC; iv:si-LAST1+si-miR-103a-3p
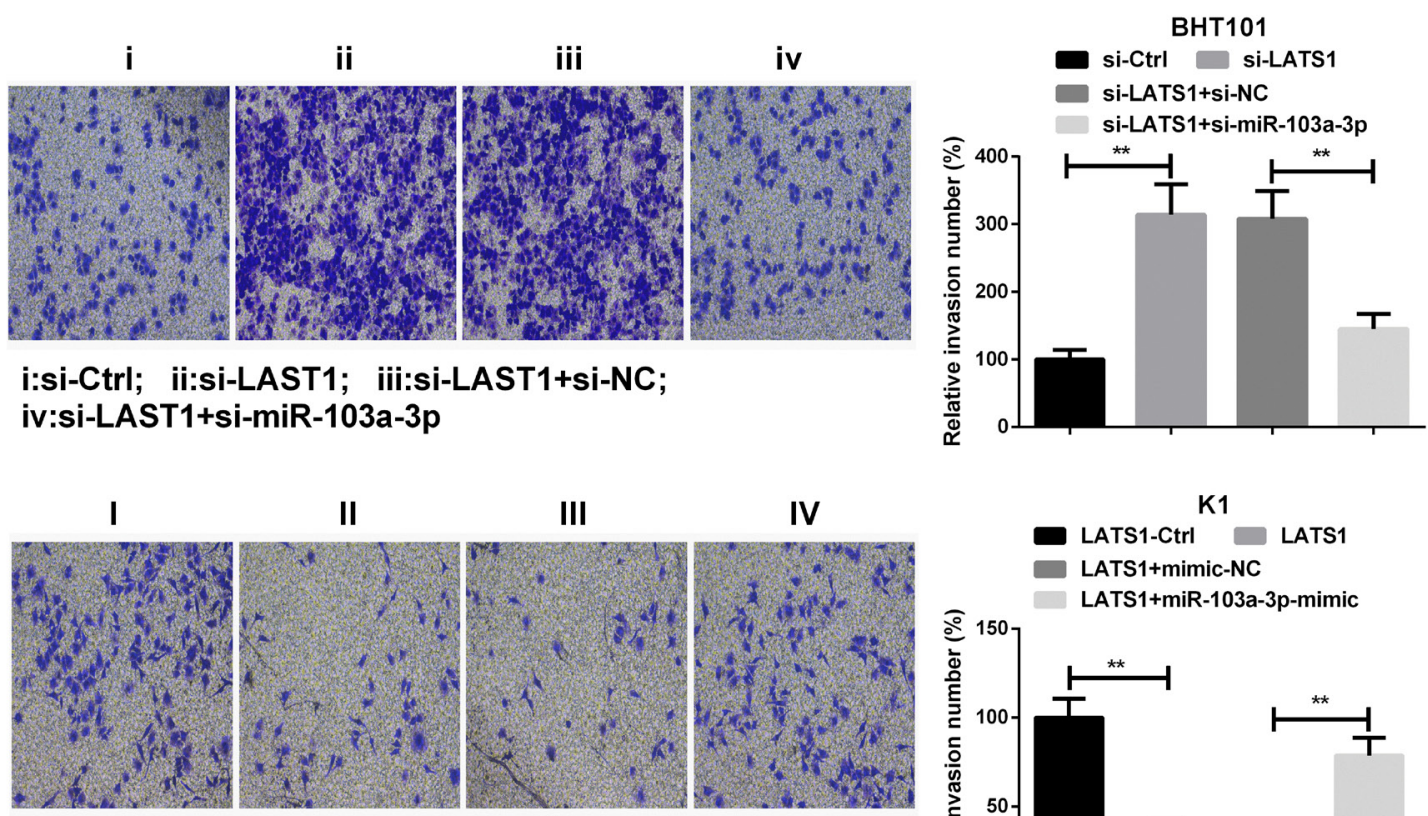

I:LAST1-Ctrl; II:LAST1; III:LAST1+mimic-NC; IV:LAST1+miR-103a-3p-mimic

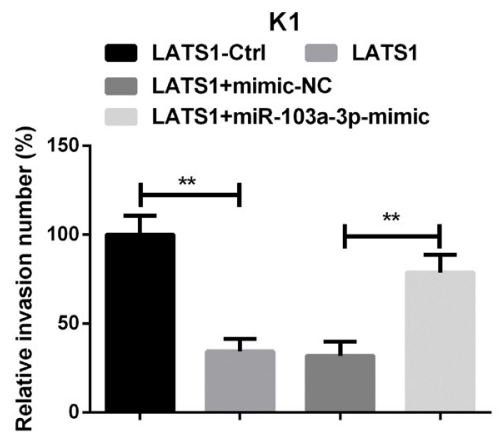

Figure 6. miR-103a-3p regulates migration and invasion of thyroid cancer cells via regulating LATS1. Wound healing assay and transwell assay were used to analyze the migration (A) and invasion (B) of BHT101 and K1 cells after transfection, respectively. ${ }^{*} \mathrm{p}<0.05,{ }^{* *} \mathrm{p}<0.01$ 
A
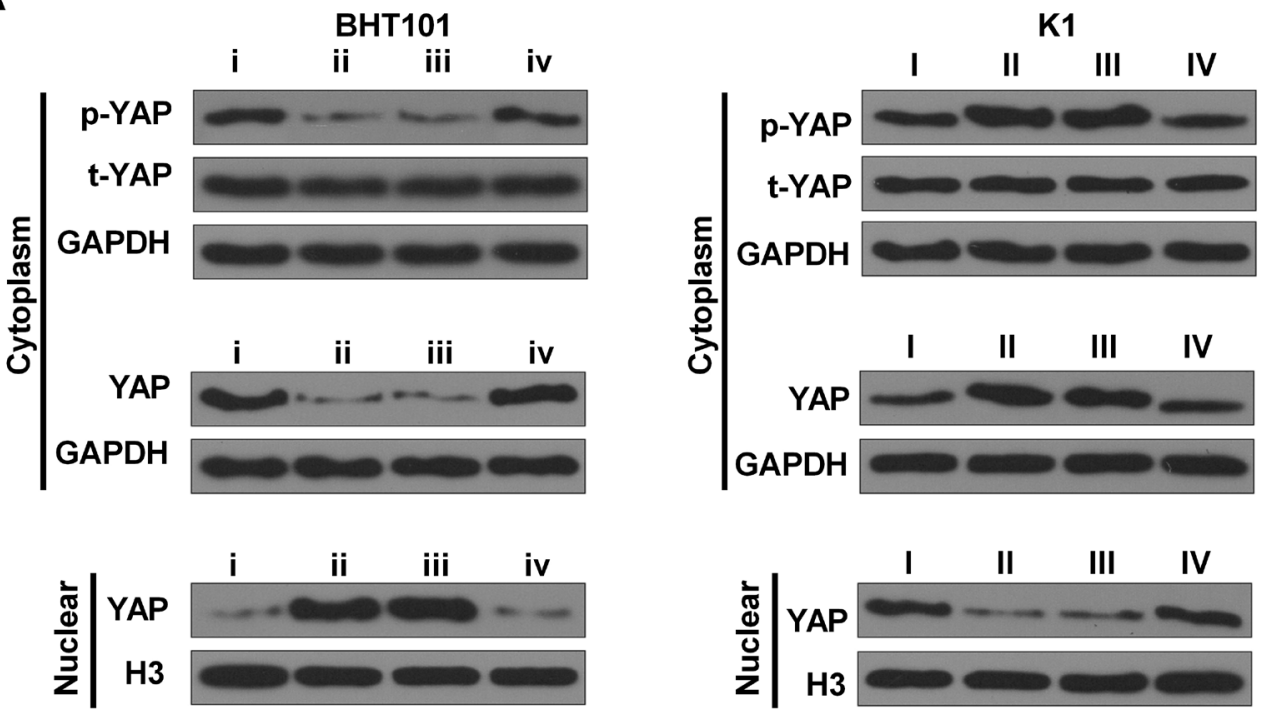

\section{i:si-Ctrl}

ii:si-LAST1

iii:si-LAST1+si-NC

iv:si-LAST1+si-miR-103a-3p

I:LAST1-Ctrl

II:LAST1

III:LAST1+mimic-NC

IV:LAST1+miR-103a-3p-mimic

B
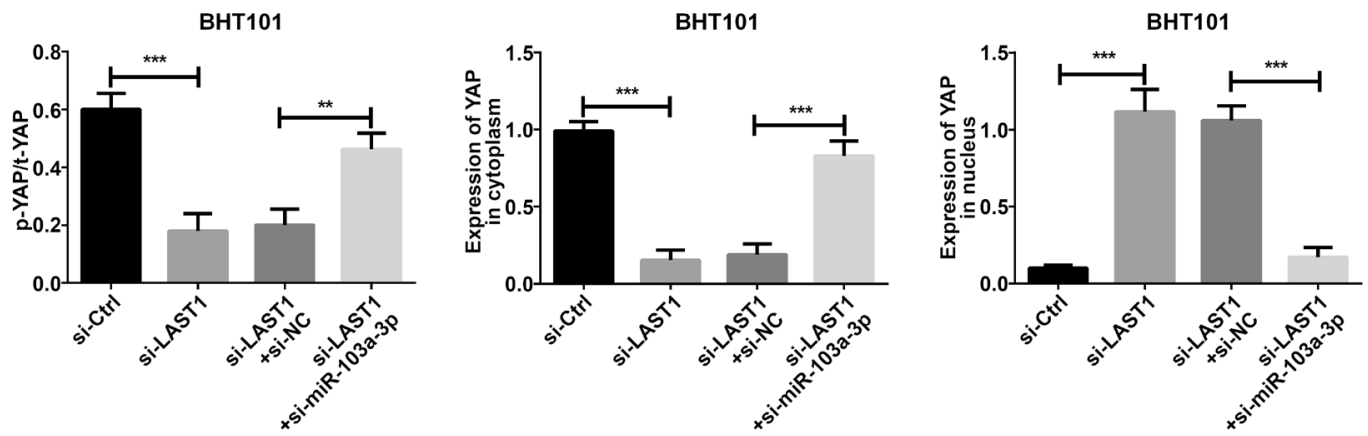

C

K1

K1
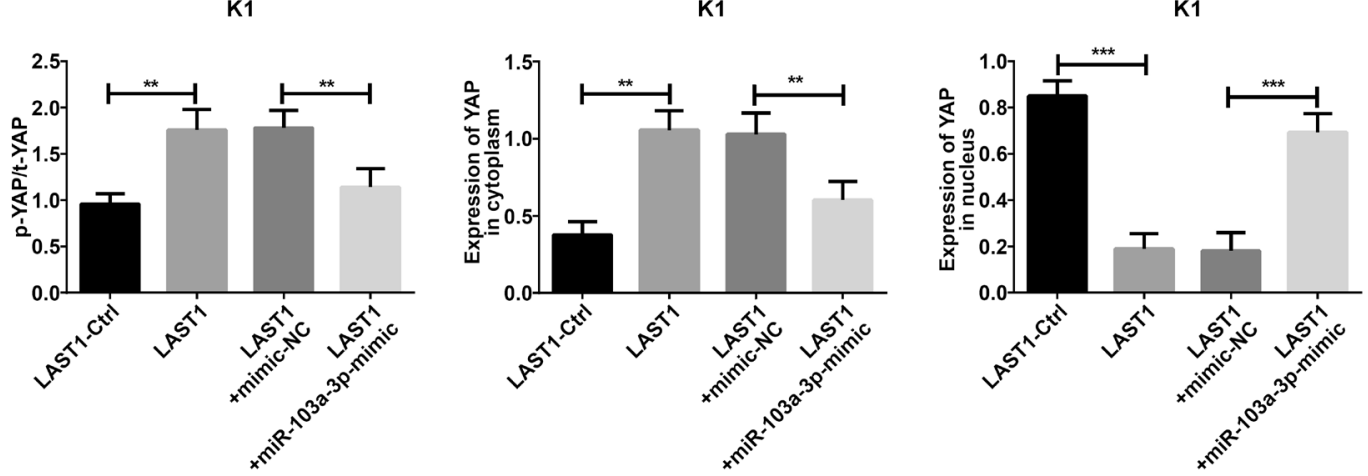

Figure 7. miR-103a-3p regulates the Hippo signaling through inhibition of LATS1. A) Western blot assay was used to analyze the expression of totalYAP ( $t$-YAP) and phosphorylated YAP (pYAP) in cells, YAP (Cyto YAP) in cytoplasm, and YAP (nuclear YAP) in the nucleus. B) LATS1 knockdown inhibited phosphorylation of YAP in BHT101 cells and promoted YAP translocation from the cytoplasm into the nucleus. While the downregulation of miR-103a-3p reversed the inhibitory effect of LATS1 knockdown on the Hippo signaling pathway. C) Overexpression of LATS1 induced YAP phosphorylation in K1 cells and inhibited YAP translocation from the cytoplasm into the nucleus. Whereas, the upregulation of miR-103a-3p reversed this effect. ${ }^{* *} \mathrm{p}<0.01,{ }^{* * *} \mathrm{p}<0.001$ 

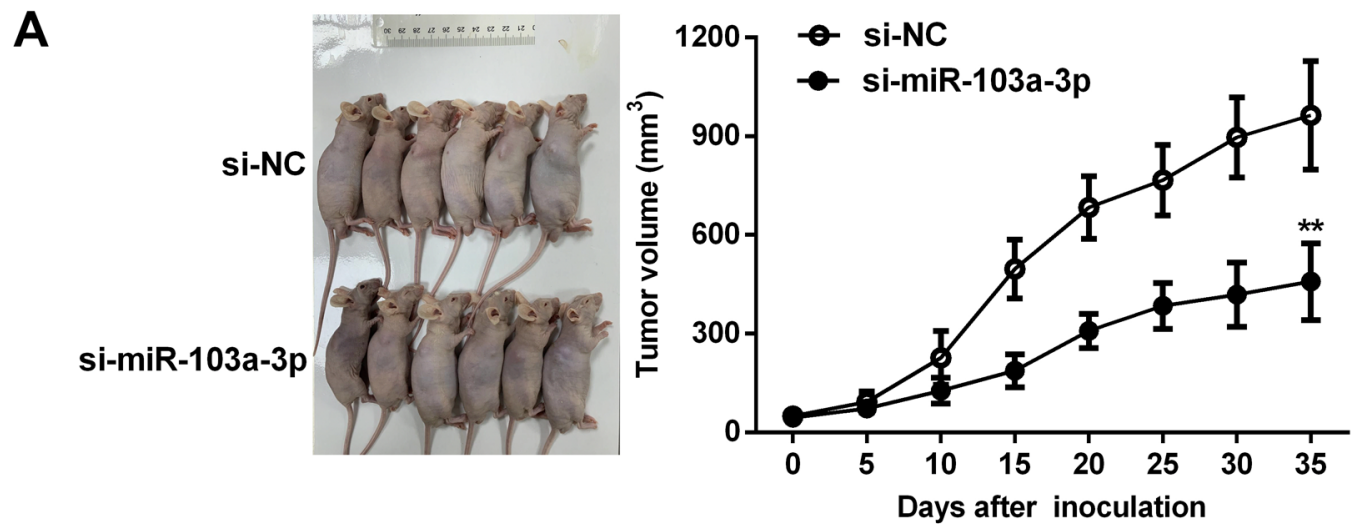

B
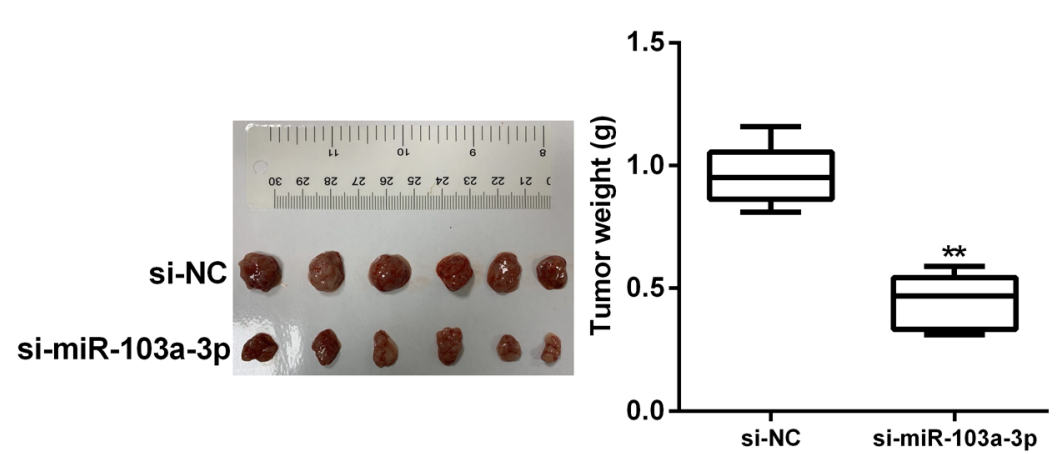

C

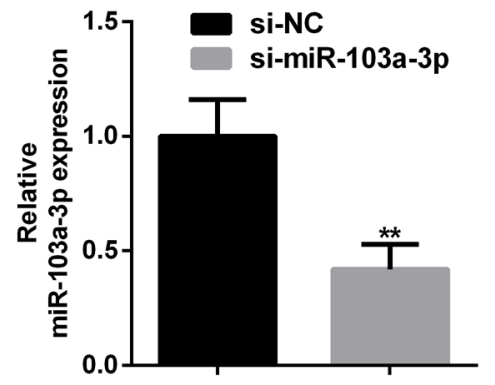

Figure 8. Knockdown of miR-103a-3p attenuates tumor growth in the xenograft model. A) Quantitative analysis of tumor volume in the xenograft tumor mice. B) Representative images of tumors and the quantitative analysis of tumor weight. C) The expression of miR-103a-3p in tumor tissues was analyzed by $\mathrm{qRT}-\mathrm{PCR} .{ }^{* *} \mathrm{p}<0.01,{ }^{* *} \mathrm{p}<0.001$

to a better understanding of the occurrence and development of thyroid cancer.

It is generally believed that the Hippo pathway has emerged as a tumor suppressor signaling that plays a crucial role in the regulation of malignant biological phenotype of cancer cells [22]. LATS is an upstream effector of the Hippo signaling pathway. Previous studies have shown that mammalian LATS is involved in tumorigenesis by regulating cell proliferation, growth, and apoptosis [30, 31]. Two mammalian homologs of LATS, LATS1 and LATS2, have been shown to be functionally conserved tumor suppressor genes [32]. YAP is a core transcriptional coactivator of the Hippo pathway $[33,34]$. LATS1 inhibits nuclear translocation through phosphorylation of YAP at multiple sites, thereby negatively regulating the transcriptional regulation and transformation of YAP [23]. If LATS1 activity is reduced, unphosphorylated YAP is transferred into the nucleus and binds to TEADs to initiate transcription of target genes, such as CTGF, CYR61, and Smad [35]. In addition, the YAP/TEADs complex activates EGFR and leads to abnormal activation of the PI3K/AKT signaling pathway, which plays a key role in tumor cell proliferation, metastasis, and drug resistance [36]. In the present study, we found that LATS1 knockdown promoted proliferation, migration, and invasion of thyroid cancer cell lines and inhibited apoptosis. Most importantly, knockdown of miR-103a-3p reversed the effects of LATS1 knockdown on thyroid cancer cells. We also examined the expression of YAP, which is the downstream gene of the LATS1 and Hippo signaling pathways. miR-103 has been demonstrated to regulate the YAP signaling pathway by targeting LATS2 [29]. However, the exact mechanism of regulation of the YAP signaling pathway by miR-103 remains unclear. We demonstrated that the knockdown of LATS1 inhibited the phosphorylation of YAP and promoted the entry of YAP into the nucleus, while the miR-103a-3p knockdown reversed the inhibitory effect of si-LATS1 on the Hippo signaling pathway. Our findings showed that miR-103a-3p regulates the nuclear translocation of YAP by targeting LATS1, thereby regulating the Hippo signaling pathway. Therefore, we hypothesized that miR-103a-3p may inhibit the Hippo signaling pathway through inhibition of LATS1, and thus participate in the development of thyroid cancer.

Taken together, this study confirmed the upregulation of miR-103a-3p expression in thyroid cancer tissues and cell lines. Through gain- and loss-of-function experiments, it 
was found that miR-103a-3p promoted proliferation, migration, and invasion and inhibited apoptosis of thyroid cancer cells. Most importantly, miR-103a-3p may be involved in the promotion of thyroid cancer through inhibition of the Hippo signaling pathway by downregulating LATS1. The results of this study suggested that inhibition of miR-103a-3p might provide insights into the treatment of thyroid cancer.

\section{References}

[1] JAVID M, GRAHAM E, MALINOWSKI J, QUINN CE, CARLING $\mathrm{T}$ et al. Dissection of Levels II Through V Is Required for Optimal Outcomes in Patients with Lateral Neck Lymph Node Metastasis from Papillary Thyroid Carcinoma. J Am Coll Surg 2016; 222: 1066-1073. https://doi. org/10.1016/j.jamcollsurg.2016.02.006

[2] LI D, WANG Q, LI N, ZHANG S. miR205 targets YAP1 and inhibits proliferation and invasion in thyroid cancer cells. Mol Med Rep 2018; 18: 1674-1681. https://doi.org/10.3892/ mmr.2018.9074

[3] EBERT MS, SHARP PA. Roles for microRNAs in conferring robustness to biological processes. Cell 2012; 149: 515-524. https://doi.org/10.1016/j.cell.2012.04.005

[4] SICILIANO V, GARZILLI I, FRACASSI C, CRISCUOLO S, VENTRE $S$ et al. MiRNAs confer phenotypic robustness to gene networks by suppressing biological noise. Nat Commun 2013; 4: 2364. https://doi.org/10.1038/ncomms3364

[5] PNG KJ, HALBERG N, YOSHIDA M, TAVAZOIE SF. A microRNA regulon that mediates endothelial recruitment and metastasis by cancer cells. Nature 2011; 481: 190-194. https://doi.org/10.1038/nature10661

[6] WANG T, XU H, QI M, YAN S, TIAN X. miRNA dysregulation and the risk of metastasis and invasion in papillary thyroid cancer: a systematic review and meta-analysis. Oncotarget 2017; 9: 5473-5479. https://doi.org/10.18632/oncotarget.16681

[7] PERDAS E, STAWSKI R, NOWAK D, ZUBRZYCKA M. Potential of Liquid Biopsy in Papillary Thyroid Carcinoma in Context of miRNA, BRAF and p53 Mutation. Curr Drug Targets 2018; 19: 1721-1729. https://doi.org/10.2174/138945 0119666180226124349

[8] YU M, XUE Y, ZHENG J, LIU X, YU H et al. Linc00152 promotes malignant progression of glioma stem cells by regulating miR-103a-3p/FEZF1/CDC25A pathway. Mol Cancer 2017; 16: 110. https://doi.org/10.1186/s12943-017-0677-9

[9] ZHANG JX, SONG W, CHEN ZH, WEI JH, LIAO YJ et al. Prognostic and predictive value of a microRNA signature in stage II colon cancer: a microRNA expression analysis. Lancet Oncol 2013; 14: 1295-1306. https://doi.org/10.1016/ S1470-2045(13)70491-1

[10] JIANG X, DU L, DUAN W, WANG R, YAN K et al. Serum microRNA expression signatures as novel noninvasive biomarkers for prediction and prognosis of muscle-invasive bladder cancer. Oncotarget 2016; 7: 36733-36742. https:// doi.org/10.18632/oncotarget.9166
[11] ZHONG Z, LV M, CHEN J. Screening differential circular RNA expression profiles reveals the regulatory role of circTCF25-miR-103a-3p/miR-107-CDK6 pathway in bladder carcinoma. Sci Rep 2016; 6: 30919. https://doi. org/10.1038/srep30919

[12] HU X, MIAO J, ZHANG M, WANG X, WANG Z et al. miRNA-103a-3p Promotes Human Gastric Cancer Cell Proliferation by Targeting and Suppressing ATF7 in vitro. Mol Cells 2018; 41: 390-400. https://doi.org/10.14348/molcells.2018.2078

[13] HE QR, ZHAO LN, LIU XB, ZHENG J, LIU YH et al. MOV10 binding circ-DICER1 regulates the angiogenesis of glioma via miR-103a-3p/miR-382-5p mediated ZIC4 expression change. J Exp Clin Cancer Res 2019; 38: 9. https://doi. org/10.1186/s13046-018-0990-1

[14] KIM W, KHAN SK, GVOZDENOVIC-JEREMIC J, KIM Y, DAHLMAN J et al. Hippo signaling interactions with Wnt/ $\beta$-catenin and Notch signaling repress liver tumorigenesis. J Clin Invest 2017; 127: 137-152. https://doi.org/10.1172/ JCI88486

[15] HEIDARY ARASH E, SHIBAN A, SONG S, ATTISANO L. MARK4 inhibits Hippo signaling to promote proliferation and migration of breast cancer cells. EMBO Rep 2017; 18: 420-436. https://doi.org/10.15252/embr.201642455

[16] HILMAN D, GAT U. The evolutionary history of YAP and the hippo/YAP pathway. Mol Biol Evol 2011; 28: 2403-2417. https://doi.org/10.1093/molbev/msr065

[17] WIERZBICKI PM, ADRYCH K, KARTANOWICZ D, STANISLAWOWSKI M, KOWALCZYK A et al. Underexpression of LATS1 TSG in colorectal cancer is associated with promoter hypermethylation. World J Gastroenterol 2013; 19: 4363-4373. https://doi.org/10.3748/wjg.v19.i27.4363

[18] ZHANG J, LIU H, HOU L, WANG G, ZHANG R et al. Circular RNA_LARP4 inhibits cell proliferation and invasion of gastric cancer by sponging miR-424-5p and regulating LATS1 expression. Mol Cancer 2017; 16: 151. https://doi. org/10.1186/s12943-017-0719-3

[19] ST JOHN MA, TAO W, FEI X, FUKUMOTO R, CARCANGIU ML et al. Mice deficient of Lats1 develop soft-tissue sarcomas, ovarian tumours and pituitary dysfunction. Nat Genet 1999; 21: 182-186. https://doi.org/10.1038/5965

[20] MOROISHI T, HAYASHI T, PAN WW, FUJITA Y, HOLT MV et al. The Hippo Pathway Kinases LATS1/2 Suppress Cancer Immunity. Cell 2016; 167: 1525-1539.e17. https:// doi.org/10.1016/j.cell.2016.11.005

[21] YU S, SHI M, LIU C, LIU Q, GUO J et al. Time course changes of oxidative stress and inflammation in hyperoxiainduced acute lung injury in rats. Iran J Basic Med Sci 2015; 18: 98-103.

[22] TAO Y, CAI F, SHAN L, JIANG H, MA L et al. The Hippo signaling pathway: an emerging anti-cancer drug target. Discov Med 2017; 24: 7-18.

[23] HAO Y, CHUN A, CHEUNG K, RASHIDI B, YANG X. Tumor suppressor LATS1 is a negative regulator of oncogene YAP. J Biol Chem 2008; 283: 5496-5509. https://doi. org/10.1074/jbc.M709037200 
[24] FASIHI A, SOLTANI BM, ATASHI A, NASIRI S. Introduction of hsa-miR-103a and hsa-miR-1827 and hsa-miR-137 as new regulators of Wnt signaling pathway and their relation to colorectal carcinoma. J Cell Biochem 2018; 119: 51045117. https://doi.org/10.1002/jcb.26357

[25] LIANG J, LIU X, XUE H, QIU B, WEI B et al. MicroRNA103a inhibits gastric cancer cell proliferation, migration and invasion by targeting c-Myb. Cell Prolif 2015; 48: 78-85. https://doi.org/10.1111/cpr.12159

[26] LIEW SK, AZMI MN, IN L, AWANG K, NAGOOR NH. Anti-proliferative, apoptotic induction, and anti-migration effects of hemi-synthetic 1'S-1'-acetoxychavicol acetate analogs on MDA-MB-231 breast cancer cells. Drug Des Devel Ther 2017; 11: 2763-2776. https://doi.org/10.2147/DDDT. S130349

[27] LEE YM, HUH KC. Clinical and Biological Features of Interval Colorectal Cancer. Clin Endosc 2017; 50: 254-260. https://doi.org/10.5946/ce.2016.115

[28] WANG X, LIN Y, PENG L, SUN R, GONG X et al. MicroRNA-103 Promotes Proliferation and Inhibits Apoptosis in Spinal Osteosarcoma Cells by Targeting p57. Oncol Res 2018; 26: 933-940. https://doi.org/10.3727/09650401 7X15144741233346

[29] HAN LL, YIN XR, ZHANG SQ. miR-103 promotes the metastasis and EMT of hepatocellular carcinoma by directly inhibiting LATS2. Int J Oncol 2018; 53: 2433-2444. https://doi. org/10.3892/ijo.2018.4580
[30] WU S, HUANG J, DONG J, PAN D. Hippo encodes a Ste20 family protein kinase that restricts cell proliferation and promotes apoptosis in conjunction with salvador and warts. Cell 2003; 114: 445-456. https://doi.org/10.1016/s00928674(03)00549-x

[31] TAPON N, HARVEY KF, BELL DW, WAHRER DC, SCHIRIPO TA et al. Salvador Promotes both cell cycle exit and apoptosis in Drosophila and is mutated in human cancer cell lines. Cell 2002; 110: 467-478. https://doi.org/10.1016/ s0092-8674(02)00824-3

[32] YU T, BACHMAN J, LAI ZC. Evidence for a tumor suppressor role for the large tumor suppressor genes LATS1 and LATS2 in human cancer. Genetics 2013; 195: 1193-1196. https://doi.org/10.1534/genetics.113.156372

[33] YAO CB, ZHOU X, CHEN CS, LEI QY. The regulatory mechanisms and functional roles of the Hippo signaling pathway in breast cancer. Yi Chuan 2017; 39: 617-629. https://doi.org/10.16288/j.yczz.17-100

[34] CAIRNS L, TRAN T, KAVRAN JM. Structural Insights into the Regulation of Hippo Signaling. ACS Chem Biol 2017; 12: 601-610. https://doi.org/10.1021/acschembio.6b01058

[35] ZHANG Q, MENG F, CHEN S, PLOUFFE SW, WU S et al. Hippo signalling governs cytosolic nucleic acid sensing through YAP/TAZ-mediated TBK1 blockade. Nat Cell Biol 2017; 19: 362-374. https://doi.org/10.1038/ncb3496

[36] ZHANG Y, YUAN J, ZHANG X, YAN F, HUANG M et al. Angiomotin promotes the malignant potential of colon cancer cells by activating the YAP-ERK/PI3K-AKT signaling pathway. Oncol Rep 2016; 36: 3619-3626. https://doi. org/10.3892/or.2016.5194 